\title{
6. Traditional Innovation and the Ongoing Debate on the Protection of Geographical Indications
}

\author{
Daniel Gervais
}

\section{Introduction}

Michel Foucault commented that the modern concept of author 'constitutes a privileged moment of individualism in the history of ideas'. ${ }^{1}$ Indeed, the authors who pushed for the adoption of international copyright rules were basking in the sun of the Enlightenment, stroked by the rays of individualism. ${ }^{2}$ The underlying Hegelian framework - a transfer of the author's personality in literary (or artistic) expression - led to an insistence on the right of attribution, a component of the moral right enshrined in the Berne Convention. ${ }^{3}$

For inventions, a similar insistence on individual self-actualisation and responsibility for scientific advances is evident. Isn't the history of science taught in schools around the world centred on individual inventors? Foucault again:

The history of knowledge has tried for a long time to obey [...] the claim of attribution: each discovery should not only be situated and dated, but should also be attributed to someone; it should have an inventor and someone responsible for it. General or collective phenomena on the other hand, those which cannot be 'attributed', are normally devalued: they

\footnotetext{
1 M Foucault, 'What is an Author?' in J Harari (ed), Textual Strategies: Perspectives in Post-Structuralist Criticism (Cornell University Press, 1979) 141.

2 The first Diplomatic Conference to negotiate the Berne Convention was held in 1884. Association Litteraire et Artistique Internationale (ALAI), an international organisation of authors, had submitted a draft which the Swiss government modified and submitted as a draft treaty. ALAI continued to take part (as what in modern parlance would be called a non-governmental organisation) in the discussions, however. ALAI was founded in 1878 by French playwright and public intellectual Victor Hugo, its first President. ALAI Congresses were held (during the relevant period) in 1879 (London); 1880 (Lisbon); 1881 (Vienna); 1882 (Rome); 1883 (Amsterdam) and 1884 (Brussels). See Actes Du Congres De Dresde (1895) 11.

3 Berne Convention for the Protection of Literary and Artistic Works (Paris Act, 1971) 1161 UNTS 18388 (1971), art 6bis.
} 
are still traditionally described through words like tradition, mentality, modes; and one lets them play the negative role of a brake in relation to 'originality' of the inventor. ${ }^{4}$

While plagium has been frowned upon for centuries, and invention has been around for at least as long (the Babylonians, Aristotle, and so on), individual invention and authorship of well-identified works and inventions - and certainly monetary rewards - emerge as normative precursors and bulwarks of 'Western' intellectual property rights. ${ }^{5}$ The Berne Convention refers several times to the author (for example, to the 'life of the author', which serves as a basis to calculate the term of protection). Similarly, the Paris Convention - though, unlike its Berne cousin, it was written not by authors or inventors but by patent and trade mark office administrators - is infused with the personality of the inventor and steeped in the nineteenth-century Western European zeitgeist. ${ }^{6}$ By contrast, many indigenous artists were seen as creating only as part of a collective. As Dan Monroe, Executive Director of the Peabody Essex Museum in Salem, Massachusetts, noted, 'recognizing that Native American art was made by individuals, not tribes, and labelling it accordingly, is a practice that is long overdue $^{\prime}{ }^{7}$

There are a few possible exceptions that come to mind, of course, but are they real exceptions in the sense of an abandonment of the premise of individuality? Not really. Most countries recognise collective works in copyright, for example, but then create the fiction that the 'arranger' is the author because of the originality she transferred to the collective work. ${ }^{8}$

\footnotetext{
4 M Foucault, quoted in Noam Chomsky and Michel Foucault, The Chomsky-Foucault Debate on Human Nature (New Press, 2006) 15.

5 See W Van Caenegem, 'Pervasive Incentives, Disparate Innovation and Intellectual Property Law', in C Arup and W Van Caenegem (eds), Intellectual Property Policy Reform: Fostering Innovation and Development (Edward Elgar, 2009) 250, 253-254. On plagiarism, see George Long, 'Plagium', in William Smith, A Dictionary of Greek and Roman Antiquities (John Murray, 1875) 921. Admittedly, this is a bit of an oversimplification. China had a complex individual v collective view of creativity during much of its imperial period. See William P Alford, To Steal a Book is an Elegant Offense: Intellectual Property Law in Chinese Civilization (Stanford University Press, 1995).

6 See Paris Convention for the Protection of Industrial Property, (Stockholm Revision Conference, 1967) 828 UNTS 305, art 4ter which states that: 'The inventor shall have the right to be mentioned as such in the patent.' If one looks at the revisions of the Paris Convention and Berne Conventions (until 1967 and 1971 respectively), one sees that all revision conferences took place in Western Europe except for a conference held in Washington in 1925. This may seem at odds with the development of innovation clusters and online innovation using 'network effects', both focusing on teamwork and on clusters on a university-governmentindustry triple helix. However, the teamwork need not annihilate individual effort and reward. See C Arup, 'Split Entitlements? Intellectual Property Policy for Clusters and Networks', in C Arup and W Caenegem (eds), above n 5, 285; and on clusters as innovation engines, see D Gervais, 'Of Clusters and Assumptions: Innovation as Part of a Full TRIPS Implementation' (2009) 77(5) Fordham Law Review 2353.

7 Quoted in J H Dobrzynski, ‘Honoring Art, Honoring Artists', New York Times (online), 6 February 2011 $<$ http://query.nytimes.com/gst/fullpage.html?res=9C06E4DFlE39F935A35751C0A9679D8B63\&pagewanted=all> She traces the beginning of the attribution movement in 'Indian art' to the 1960s. 
Yet there is one area of intellectual property which bucks this philosophiccultural trend: the protection of geographical indications (GIs). In fact, it is not entirely clear whether this area is 'intellectual property'. ${ }^{9}$ Its underlying premise is different: it holds that a combination of natural and human (but not individual) factors anchored in (usually longstanding) tradition can give certain products special characteristics. These unique admixtures - sometimes referred to as terroir - are both commercial instruments and symbols of national or regional identity. ${ }^{10}$

A system of protection for denominations of origin uses that combination as a marketing tool to extract additional rent in various commercial offerings, but also to affirm the special nature of the place it designates as the origin of a GI product. Put differently, the consumer is asked to pay more (or less) because the GI validates not just the factual claim that a white wine made with Sauvignon grapes will not be the same - even if made by the same person using the same technique - in the Loire valley of France and the Marlborough region of New Zealand, but that its origin reflects both a know-how and natural conditions that make that wine 'special'. ${ }^{11}$ Wine experts agree that the acidity of the soil, and the amount of rain and sun exposure will affect the outcome, but the GI does even more: it recognises a collective right of producers in a given region to claim and capture the (real or perceived) special quality or characteristic of the product.

A legal mechanism, namely the 1958 Lisbon Agreement for the Protection of Appellations of Origin and their International Registration, was designed to capture that special value and protect it against usurpation or imitation. ${ }^{12}$ As such, it could mesh well with forms of traditional innovation and both old and new forms of economic exploitation of traditional knowledge related to crafts or food. It could conceivably extend to other forms of innovation (for example,

9 Convention Establishing the World Intellectual Property Organization, (1967) 848 UNTS 3, art 2 defines intellectual property as follows: "'intellectual property" shall include the rights relating to: literary, artistic and scientific works, performances of performing artists, phonograms, and broadcasts, inventions in all fields of human endeavor, scientific discoveries, industrial designs, trademarks, service marks, and commercial names and designations, protection against unfair competition, and all other rights resulting from intellectual activity in the industrial, scientific, literary or artistic fields'. The only possible pigeonhole for GIs would be as commercial designations or perhaps a general form of unfair competition regulation.

10 'The notion that food is both sacred and site-specific is the root of the emotionally charged French concept of "terroir." First applied to describe the association of grape variety and soil in winemaking, it has come to evoke the wholesome, earthy qualities of regional foods and cooking.', D Downie, 'Let Them Eat Big Macs', Salon (online), 7 July 2000, <http://www.salon.com/business/feature/2000/07/06/frenchfood/index. htm> D Menival, 'The Greatest French AOCs: A Signal of Quality for the Best Wines' (Working Paper 1, 2007) $<$ http://www.vdqs.net/Working_Papers/Text/WP_2007/Menival_249.pdf>

11 Among the soil-related factors that are most important are the drainage capacity, salinity, and the ability of the soil to retain heat, thus encouraging ripening and the development of stronger roots. See D Bird, Understanding Wine Technology: The Science of Wine Explained (Wine Appreciation Guild, 2005) 1.

12 Lisbon Agreement for the Protection of Appellations of Origin and their International Registration (Stockholm Revision, 1967 and amended 1979) 923 UNTS 205. 
traditional medicinal products) if one of the perceived characteristics of the product was anchored in a specific region because the land has a special quality, because the inhabitants have a special way of exploiting it, or both.

In this chapter, I proceed as follows. I discuss, first, the Lisbon Agreement and then the more recent Agreement on Trade-Related Aspects of Intellectual Property Rights (TRIPS Agreement) in the WTO context. This rather technical analysis is then broadened to consider how GIs mesh normatively with the protection of traditional innovation. ${ }^{13}$ Finally, I suggest possible changes to the Lisbon Agreement, some of which are under consideration at the World Intellectual Property Organization (WIPO), as of the time of writing, that would allow some forms of traditional innovation to benefit from a reform of the international protection of GIs.

\section{The Lisbon Agreement}

To understand the Lisbon Agreement, let us consider briefly its current membership and current use; whether what it protects - namely 'appellations of origin' - are different from the 'geographical indications' protected under the TRIPS Agreement; and then the way in which it operates both substantively (scope of protection) and administratively (as a register of geographical denominations).

\section{(a) Membership and Current Use}

There were only twenty-seven countries party to the Lisbon Agreement as of June 2012. ${ }^{14}$ As such, it cannot be said to have established a worldwide system of protection for geographical denominations used in association with specific products. That said, there has been progress in recent years: approximately one-third of the Lisbon member states joined after the conclusion of the TRIPS Agreement in $1994 .{ }^{15}$ In spite of those additions, however, the Agreement's membership is still largely concentrated in the Mediterranean world. An

\footnotetext{
13 See also M Blakeney, 'The Pacific Solution: The EU's IPR Activism in Australia's and New Zealand's Sphere of Influence', ch 8 in this volume.

14 Algeria, Bulgaria, Burkina Faso, Congo, Costa Rica, Cuba, Czech Republic, Democratic People's Republic of Korea, France, Gabon, Georgia, Haiti, Hungary, Iran (Islamic Republic of), Israel, Italy, the former Yugoslav Republic of Macedonia (FYROM), Mexico, Montenegro, Nicaragua, Peru, Portugal, Republic of Moldova, Serbia, Slovakia, Togo and Tunisia. Greece, Morocco, Romania, Spain and Turkey signed the 1958 Agreement but never ratified it.

15 Democratic People's Republic of Korea (2005), FYROM (2010), Georgia (2004), Iran (2006), Montenegro (2006), Nicaragua (2006), Peru (2005) and Moldova (2001). It is worth noting that sui generis systems (as separate from trade mark law) exist in approximately 75 countries. See I Kireeva and B O'Connor, 'Geographical Indications and the TRIPS Agreement: What Protection Is Provided to Geographical Indications in WTO Members?' (2010) 13(2) Journal of World Intellectual Property 12.
} 
examination of all current appellations on the register shows that almost all emanate from fewer than ten countries. Indeed, eleven countries hold 97.5 per cent of all entries, and in fact the top three hold over 78 per cent, with one country, France, holding 62.5 per cent of the total (almost 90 per cent of which are for wines and spirits). ${ }^{16}$ In terms of product areas, of the 813 accessible entries on the register, ${ }^{17} 588$ (72.3 per cent) were for wines and spirits (519 for wines, and thus potentially of interest for the Article 23.4 register) and an additional 11 for beer. ${ }^{18}$

\section{(b) Appellations of Origin v Geographical Indications}

One feature of the Lisbon system is that it applies to 'appellations of origin'. By contrast, the TRIPS Agreement uses the expression 'geographical indications'. Is there a difference? This will matter when deciding where to house a new GIs system. The Lisbon Agreement defines 'appellations of origin' as follows:

[...] the geographical name of a country, region, or locality, which serves to designate a product originating therein, the quality or characteristics of which are due exclusively or essentially to the geographical environment, including natural and human factors. ${ }^{19}$

Appellations of origin are denominations that designate a geographical location to distinguish products produced in that location, and produced either according to regulations or 'local, constant and trusted usage' ${ }^{20}$ in such location, which results in a certain quality or characteristics of the product and in the acquisition of a reputation.

The notion of 'geographical indication' used in TRIPS also focuses on the quality or characteristics of goods that derive from a geographical origin. ${ }^{21}$ However, TRIPS adds a measure of semiotic flexibility by encompassing any indication (denomination or otherwise) that would point to a particular geographic origin as long as a certain quality or characteristic (and/or reputation) is attributable to that origin. That difference seems theoretical today, because the current practice under the Lisbon Agreement is to register denominations that may not be 'denominations' stricto sensu. ${ }^{22}$

16 Data extracted from the Lisbon Express Database <http://www.wipo.int/ipdl/en/lisbon/>

17 As of 10 December 2009. See WIPO, Search Appellations of Origin (Lisbon Express) < http://www.wipo. int/ipdl/en/search/lisbon/search-struct.jsp>

18 I separated wines and spirits from other products, including beer, following in the footsteps of the TRIPS Agreement, art 3.

19 Lisbon Agreement, above n 12, art 2(1), emphasis added. Quality or characteristics should include natural factors because human factors are moveable and thus hard to pinpoint geographically.

20 Actes De La Conférence Réunie À Lisbonne Du 6 Au 31 Octobre 1958 (Actes) (BIRPI, 1963) 813. The Acts of the Lisbon Conference were published in French. All translations are the author's own.

21 TRIPS Agreement, art 22.1.

22 M Ficsor, Challenges to the Lisbon System, WIPO Doc WIPO/GEO/LIS/08/4 (2008). 
Another difference is in the treatment of reputation. The Lisbon Agreement defines 'country of origin' as 'the country whose name, or the country in which is situated the region or locality whose name, constitutes the appellation of origin which has given the product its reputation. ${ }^{23}$ Lisbon focuses on quality and characteristics that provide a reputational advantage (the land, its particular use or, more typically, both), while TRIPS lists the three notions as separate phenomena that may emerge from the link to a specific geographic origin. It is essential to bear in mind that reputation is only a mental link between that product and a perceived quality or characteristic tied to a geographical origin. Put differently, if potential buyers of a product want it because a quality or characteristic associated with it stems from its geographical origin (whether the cause is human or natural factors, or a combination of both), then that product may be said to have a given reputation. ${ }^{24}$

\section{(c) Scope of Protection}

If TRIPS and Lisbon apply to essentially the same subject matter, is the scope of protection in the two instruments comparable? Article 3 of the Lisbon Agreement provides that protection must be conferred against usurpation or imitation, even if the true origin of the product is indicated or the appellation is accompanied by terms such as 'kind', 'type', 'make', 'imitation' or the like. ${ }^{25}$ The Actes define usurpation as the 'illicit adoption' of an appellation (and provide counterfeiting as a possible synonym) and, as to the latter, refer to 'fraudulent imitation'. ${ }^{26}$ This seems reasonably limited in scope. The Actes also make it clear that it is up to each country to decide what remedies should be available. ${ }^{27}$ There is thus sufficient implementation flexibility to accommodate different legal systems. I will suggest below that a protocol to the Agreement should be added to the current framework. One of its key purposes would be to align the Lisbon terminology and prohibitions with the TRIPS language to avoid the inherent risks associated with a dual standard of protection.

Determining the scope of protection also means determining how conflicts with prior trade marks might be handled. The Lisbon Agreement allows, but does not obligate, its members to adopt or continue to use: (1) the 'first in time, first in right' approach, as promoted, inter alia, by the International Trademark Association (INTA) ${ }^{28}$ and the International Association for the Protection of

23 Article 2(2) provides that the 'country of origin is the country whose name, or the country in which is situated the region or locality whose name, constitutes the appellation of origin which has given the product its reputation' [emphasis added].

24 See WIPO IGC Secretariat, Geographical Indications, WIPO doc SCT/10/4 (2003), para 25.

25 Lisbon Agreement, above n 12, art 3 [emphasis added].

26 Actes, above $\mathrm{n} 20$.

27 Actes, above n 20, 818.

28 INTA, Resolution on Protection of GIs and Trademarks (1997) < http://www.inta.org $>$ See also the General 
Intellectual Property (AIPPI); ${ }^{29}$ (2) a co-existence approach (that is, a GI and trade mark with similar legal effect); ${ }^{30}$ or (3) a GI superiority approach. Members may do so with or without a good faith requirement concerning the prior trade mark. ${ }^{31}$ Some members actually use more than one approach. GIs have superior rights over prior trade marks in EC Regulation 1493/1999, ${ }^{32}$ which provides for discontinuation of the use of a prior trade mark if a confusingly similar designation is later on protected as a GI for wine; but EC Regulation 2081/92 ${ }^{33}$ and amended Council Regulation (EEC) No. 2392/89 provide for co-existence under certain conditions between a prior trade mark and a later GI (but not vice versa); and Article 3(4) of Regulation 510/2006 $6^{34}$ provides that a 'designation of origin or geographical indication shall not be registered where, in the light of a trademark's reputation and renown and the length of time it has been used, registration is liable to mislead the consumer as to the true identity of the product'. The United States and most if not all countries that protect GIs under trade mark law prefer, and would likely insist on, the 'first in time, first in right' approach. ${ }^{35}$ As noted below, a refusal under Lisbon can be partially withdrawn to allow co-existence with a prior trade mark for an indefinite period or to allow co-existence of homonymous denominations.

29 See AIPPI, 'Resolution on Q62' (Yearbook 1998/VIII) 389-392. The acronym comes from the original (French) version of the Association's name, the Association internationale pour la protection de la propriété intellectuelle.

30 This can also be the case between two appellations. By using a declaration of partial refusal, a country may allow an appellation but preserve the right of another country to use that same appellation, as was done for Pisco. Mexico, for instance, refused Pisco but only to the extent that the registration by Peru 'constitutes an obstacle to products from Chile bearing the denomination of origin Pisco'. Mexico's withdrawal of refusal is dated 24 October 2006 [author's translation].

31 In WTO Panel Report, European Communities - Protection of Trademarks and Geographical Indications for Agricultural Products and Foodstuffs, (Australian Report), WTO Doc WT/DS290/R (2005), the panel seemed to conclude that the first two options are TRIPS compatible, though there are some constraints on the second. There is a doubt as to the TRIPS compatibility of the third option.

32 Council Regulation (EC) No 1493/1999 of 17 May 1999 on the Common Organisation of the Market in Wine [1999] OJ L 179, annex VII at point F.

33 Council Regulation (EEC) No 2081/92 of 14 July 1992 on the Protection of Geographical Indications and Designations of Origin for Agricultural Products and Foodstuffs [1992] OJ L 208.

34 Council Regulation (EC) No 510/2006 of 20 March 2006 on the Protection of Geographical Indications and Designations of Origin for Agricultural Products and Foodstuffs [2006] OJ L 93 (which replaced Council Regulation 2081/92, ibid, following the WTO panel case dealing with GI protection in the European Union, see European Communities, above n 31).

35 'For marks that are geographically descriptive of the origin of particular goods, the first person that establishes acquired distinctiveness may be able to prevail against a person attempting to use a similar mark where the latter cannot show acquired distinctiveness', see A Simpson et al, 'The Relationship between Trademarks and Geographical Indications' (United States Group Report Q191/AIPPI Report 11, 2006) <http:// www.aippi-us.org/images/AIPPI-Q191(2006)(2).DOC> 11. According to Irena Kireeva and Bernard O'Connor, the United States, Canada, Australia, Japan, and many African and Arab countries protect geographical denominations of origins associated with certain products under trade mark law. See I Kireeva and B O'Connor, above n 15, 12 . 


\section{(d) Registration}

Applications for registration on the Lisbon register may be made only by or through the appointed authority of a member state. ${ }^{36}$ The national authority applies in the 'name of any natural persons or legal entities, public or private, having, according to their national legislation, a right to use such appellations' ${ }^{37}$ Two conclusions can already be drawn: (a) a national authority must be appointed to interface with the Lisbon register; and (b) it is up to each country of origin to decide who has the right to register a Lisbon appellation. ${ }^{38}$

Are Lisbon members obligated to accept any appellation registered by another member? The dispute resolution component of the system is simple: any national office may declare that it 'cannot ensure the protection of an appellation of origin whose registration has been notified to it ... together with an indication of the grounds therefore'. ${ }^{39}$ This declaration of refusal must be made within one year of the receipt of WIPO's notification and may not be made later. ${ }^{40}$ If a declaration of refusal is made within the appropriate timeframe and with justification, WIPO then notifies the country of origin which, in turn, notifies the applicant. The only remedy available at that juncture for the applicant/right holder is to resort, in the refusing country, to the judicial and administrative remedies open to the nationals of that country.

Moreover, there are no limits imposed on the grounds that may be invoked in support of a declaration of refusal under Article 5(3). The negotiating history provides one example: when a member considers that an appellation has become generic in its territory. ${ }^{41}$ There are several other grounds for a refusal, however. ${ }^{42}$ The Actes show

36 Lisbon Agreement, above n 12, art 5. The official French text speaks of 'administration compétente'. See M Geuze, Let's Have Another Look at the Lisbon Agreement: - Its Terms in Their Context and in the Light of Its Object and Purpose WIPO Doc WIPO/GEO/BEI/07/10 (2007).

37 Lisbon Agreement, above n 12, art 5(1). The obligation to apply through a national authority is similar under the Madrid system (trade marks). See Madrid Agreement Concerning the International Registration of Trademarks, 828 UNTS 389 (1891) and the Protocol Relating to the Madrid Agreement Concerning the International Registration of Marks (1989) 28 Industrial Property Law and Treaties 3-007, 001. One potential difference is whether the national authority is required to pass on an application to the international level (WIPO) or whether it could refuse to do so if it considered the application unfounded. The latter is certainly permissible under Lisbon.

38 Regulations under the Lisbon Agreement for the Protection of Appellations of Origin and Their International Registration, above n 12, art 4 provides that each country must inform WIPO of the name and address of the authority competent to effect each of the notifications possible under the Agreement.

39 Ibid, art 5(3).

40 Ibid, art 5(4).

41 In a document prepared for the recently established Working Group on the Development of the Lisbon System, the WIPO Secretariat notes: '[A] contracting country may refuse to protect an appellation of origin because it considers that the appellation has already acquired a generic character in its territory in relation to the product to which it refers or because it considers that the geographical designation does not conform to the definition of an appellation of origin in the Lisbon Agreement or because the appellation would conflict with a trademark or other right already protected in the country concerned.' WIPO Doc, Possible Improvements of The Procedures Under The Lisbon Agreement, WIPO Doc LI/WG/DEV/1/2 (2009), annex II, 4 [emphasis added] < http://www.wipo.int/ edocs/mdocs/mdocs/en/li_wg_dev_1/li_wg_dev_1_2_rev.pdf $>$ The Working Group was established at the twentythird (6th extraordinary) session of the Assembly of the Lisbon Union (22-30 September 2008) and is responsible for exploring possible improvements to the procedures under the Lisbon Agreement. The Working Group met in Geneva from 17-20 March 2009. See the Summary by the Chair, WIPO doc LI/WG/DEV/1/3 (2009). 
that Italy suggested an amendment to limit refusals only to cases where an appellation has become generic in the declaring country, and this amendment was refused by a vote of $7-1 .{ }^{43}$ Other possible grounds for refusal include cases where an appellation is used for a product that violates ordre public, ${ }^{44}$ and cases where what was registered is not considered a proper appellation. ${ }^{45}$ The Actes make that clear: "The proposed procedure gives countries which receive the notification of an appellation of origin from the International Bureau the possibility of using any legal or factual situation to oppose the grant of protection for all or part of the territory of the Special Union. ${ }^{.46}$

As a possible alternative to a refusal, Article 5(6) of Lisbon provides that if an appellation which has been granted protection in a given country pursuant to notification of its international registration was already in use by third parties in that country - and assuming that no refusal is notified under Article 5(3) - such third parties may be given a delay of up to two years to cease using the appellation. ${ }^{47} \mathrm{~A}$ notification to WIPO is required.

The twelve-month period to notify a refusal is not quite the last word. Under Lisbon Rule 16, a Lisbon member may invalidate a registered appellation. Once the invalidation is final (usually after all rights to appeal have been used or expired), it must be notified to the International Bureau. ${ }^{48} \mathrm{~A}$ court or other competent authority in the country where protection is claimed can invalidate an appellation for any reason.

The fundamental underpinning of the Article 5 registration system is thus that the system, and especially the decision to file a declaration of refusal, is administered by each member state. The negotiating history makes plain that the negotiators did not want an international supervisory or oversight authority. ${ }^{49}$ A Lisbon member can refuse any appellation notified to it. If and when approached by the country of origin, it may negotiate the withdrawal of such refusals ${ }^{50}$ in the same way that bilateral agreements are now negotiated to protect certain GIs. ${ }^{51}$ The Actes are similarly clear in that respect: 'The refusal

43 Actes, above n 20, 835-837.

44 As Iran did in refusing 'PILS'. See IRAN - Declaration of Refusal of Protection, Appellation 001 and 002

(10 December 2007). Iran joined Lisbon in 2006.

45 The appellation 'Bud' (Appellation 598) was similarly refused by many Lisbon members as not referring

to a geographical location. The case also highlights the differences between appellations and trade marks.

46 Actes, above n 20, 817 [author's translation].

47 See also Regulations made under the Lisbon Agreement, above n 12, rule 12.

48 For example, the appellation 'Bud', which was refused by several Lisbon members, was invalidated in Hungary, Italy and Portugal, see Lisbon Registration 598. The Italian invalidation refers to a final decision by the Italian Supreme Court no. 13168/02 of 18 June 18 2002, confirming a decision by the Court of Appeal of Milan. See Lisbon Bulletin No. 37 <http://www.wipo.int/lisbon/en/bulletin/archive.html>

49 Actes, above n 20, 836.

50 A mechanism to withdraw declarations of refusal is provided in the Lisbon Regulations, above $\mathrm{n} 12$, art 11.

51 For example, in 2005 a bilateral agreement was reached between Europe and the United States on products of the vine. See B Rose, 'No More Whining about Geographical Indications: Assessing the 2005 Agreement between the United States and the European Community on the Trade in Wine' (2007) 29 Houston 
must be accompanied by the grounds for which the country has decided not to grant protection. Those grounds constitute a basis for possible discussion with a view to arriving at an agreement. ${ }^{.52}$

There is, however, one substantive limit to refusals: Article 6 of the Lisbon Agreement provides that a registered appellation cannot be deemed to have become generic as long as it remains protected in the country of origin. ${ }^{53}$ The expression 'deemed to have become' plainly refers to an evolution in time. Put differently, genericness is not an event; it is a process. As noted in a WIPO document, Article 6 is not as harsh as it sounds: 'Exceptions to this general rule may apply, in particular in cases of acquiescence, i.e. if the exclusive right to use the appellation of origin has not been enforced vis-à-vis certain persons, who are using the appellation of origin in respect of products that do not meet the specific geographically-determined qualifications linked to the appellation of origin. ${ }^{54}$ This seems to imply that a Lisbon member may, in bilateral discussions, recognise the generic nature of one of its appellations in another member's territory.

\section{The TRIPS Agreement}

There are two main areas where differences between TRIPS and Lisbon appear - apart from the difference between the notions of geographical indication and of appellation of origin, discussed in the previous section. The first is the dual level of protection in TRIPS, and its special treatment of wines and spirits. The other is the presence of a number of conflict rules that go well beyond the possibility of a refusal in Lisbon. I will consider each one in turn.

\section{(a) Two Levels of Protection}

The TRIPS Agreement provides for two types of protection of GIs. Article 22.2 obliges WTO members to provide Paris-type protection for GIs. That level of protection is described here as 'legal means' for interested parties to prevent (a) the use of any means (not limited to a name) ) $^{55}$ in the designation or presentation of a good that could mislead the public into believing that the good in question originated in a geographical area other than the true place of origin; or (b) any

\footnotetext{
Journal of International Law 731.

52 Actes, above n 20, 817 [author's translation]. A number of proposed amendments to the Rules would streamline the system. See WIPO Doc, Report adopted by Assembly, LI Doc LI/A/25/1 (2009), annex 1.

53 Lisbon Agreement, above n 12, art 6.

54 Geuze, above n 36, 8.

55 It would seem that the reference to 'any means in the designation or presentation', combined with the open-ended mention of 'indication which identify a good' (regardless of the means), covers also indirect indications.
} 
use which constitutes an act of unfair competition within the meaning of Art.10 bis of the Paris Convention. This provision does not create a full exclusive right. ${ }^{56}$ Significantly, under Article 22.2 (a), one must show that the public might be misled - a level of protection that resembles trade mark law. ${ }^{57}$ In fact, protection of GIs may be provided as collective or certification marks. ${ }^{58}$

TRIPS provides a higher (Lisbon-type) ${ }^{59}$ level of protection for wines and spirits. ${ }^{60}$ Using a GI identifying wines or spirits for those not originating in the place indicated by the indication is prohibited, even where the true origin of the wines and spirits concerned is indicated and/or a translation is used and/ or the indication is accompanied by expressions such as 'kind', 'type', 'style', 'imitation' or the like. There is no need here to show that the public might be misled or that the use constitutes an act of unfair competition. Under Article 22.3, a WTO member must, either ex officio if its national law so permits, or at the request of an interested party, refuse or invalidate ${ }^{61}$ the registration of a trade mark which contains or consists of a GI if (a) the goods do not originate in the territory indicated; and (b) use of the indication in the trade mark for such goods in the territory of the 'Member' concerned is of such a nature as to mislead $^{62}$ the public as to the true place of origin. ${ }^{63}$ Article 23.2 more or less corresponds to Article 22.3, but applies specifically to indications identifying wines and spirits, except of course that deception (misleading the public as to the true place of origin) need not be present.

\section{(b) Conflicts with Prior Trade Marks}

Important conflict rules between GIs and trade marks are contained in TRIPS Articles 24.5 and 24.6. Under the former, a GI conflicting with a trade mark does not supersede the mark, provided that an application for registration of the mark was filed or the mark registered, or the right acquired by use (and the trade mark was in fact used in good faith ${ }^{64}$ in the WTO member concerned either

\footnotetext{
56 Civil judicial procedures must be available to the right holder, TRIPS Agreement, art 42.

57 See J T McCarthy, McCarthy on Trademarks and Unfair Competition (4th ed, Clark Boardman Callaghan, 2002), para 2:35.

58 See J Hughes, 'Champagne, Feta, and Bourbon: The Spirited Debate about Geographical Indications' (2006) 58 Hastings Law Journal 299, 310.

59 McCarthy, above n 57, para 29.28.

60 TRIPS Agreement, art 23.1.

61 Compare with 'cancellation' in arts 15 and 19.

62 Article 22(2)(a) uses 'which misleads', Article 10bis(3) of the Paris Convention uses 'is liable to mislead' and Article 22(3) uses 'is of such a nature as to mislead'. The latter two tests seem very close indeed. The likelihood that the public will be misled may, as in the case of trade marks, be inferred in appropriate circumstances.

63 This element could exclude marks having acquired a secondary meaning.

64 This test is sometimes difficult to apply, as evidence of good (or bad) faith is not always easy to produce. Showing bad faith based entirely on circumstances is sometimes rendered more difficult in legal systems that presume good faith until the contrary is shown. In applying the test, the fact that an indication is particularly
} 
before the TRIPS Agreement became applicable in the member concerned, ${ }^{65}$ or before the indication in question was protected in its country of origin. ${ }^{66} \mathrm{~A}$ WTO panel examining the $E C$ - Trademarks and Geographical Indications dispute explained that the co-existence of a protected indication and a trade mark was a limited exception justified under TRIPS Article $17 .{ }^{67}$ The purpose is to allow a trade mark to be registered (and registration applied for) and used, even if it is identical with or similar to a GI, ${ }^{68}$ provided, however, that the trade mark is at least applied for (including if it was registered, naturally) or the rights acquired through use, either before the WTO member concerned must apply Article 23 or before the indication is protected in its country of origin.

Article 24.6 is also relevant in this context. It provides that WTO members may decide not to protect a GI used in connection with foreign goods or services for which the relevant indication is identical with the term customary in common language as the common name for such goods or services in the territory of that member ${ }^{69}$ It also states that members are not required to protect foreign GIs 'with respect to products of the vine for which the relevant indication is identical with the customary name of a grape variety existing in the territory of that member as of the date of entry into force of the WTO Agreement ${ }^{\prime}{ }^{70}$

\section{Traditional Innovation and GIs}

\section{(a) Types of Traditional Knowledge in Traditional Innovation}

In 2003, I suggested that one should distinguish four types of traditional knowledge (TK). ${ }^{71}$ This type of knowledge is likely to be a major source of traditional innovation and development. In thinking about this matrix, the

well known and/or used (directly or indirectly) by undertakings located in or near the 'true' place of origin should be taken into account. See AIPPI, 'Working Guidelines Q191: Relationship Between Trademarks and Geographical Indications' (Yearbook 2006/II), 18.

65 For the most industrialised nations, 1 January 1996. See TRIPS Agreement, art 65.1. For developing countries other than least-developed ones, most substantive provisions of the Agreement applied as of 1 January 2000.

66 See WIPO Doc, Possible Solutions for Conflicts Between Trademarks and Geographical Indications and for Conflicts Between Homonymous Geographical Indications, WIPO Doc SCT/5/3 (2000), 11-12.

67 WTO Panel Report, European Communities - Protection of Trademarks and Geographical Indications for Agricultural Products and Foodstuffs, (US Report) WTO Doc WT/DS174/R (2005); European Communities, above n 31. The Panel concluded, 'with respect to the coexistence of GIs with prior trademarks, the Regulation is inconsistent with Article 16.1 of the TRIPS Agreement but, on the basis of the evidence presented to the Panel, this is justified by Article 17 of the TRIPS Agreement.' US Report, para 7.688 and European Communities (Australian Report), above n 31, para 7.686.

68 See Lisbon Agreement, above n 12, art 5(6); and F Gevers, 'Geographical Names and Signs Used as Trade Marks' (1990) 8 European International Property Review 285.

69 See TRIPS Agreement, art 24.6.

70 See ibid [emphasis added].

71 D Gervais, 'Spiritual but Not Intellectual? The Protection of Sacred Intangible Traditional Knowledge' (2003) 11 Cardozo Journal of International and Comparative Law 467. 
question to be answered is whether GIs may be used to capture the special value attributed to products embodying TK and, more particularly, any special value associated with a geographic origin following from the land the product comes from and/or the way in which the people living on that land produce the product.

The TK matrix I suggested looked as follows:

\begin{tabular}{|l|l|}
\hline I sacred tangible & II secular tangible \\
\hline III sacred intangible & IV secular intangible \\
\hline
\end{tabular}

Q1 includes rights, including property rights in tangible objects used as part of or pertaining to something sacred. Examples include sacred sites.

Q2 includes rights in photographs, choreographies, music or audiovisual productions used in non-sacred events and ceremonies and often offered for sale to visitors and tourists;

Q3 includes intellectual property and other intangible rights applicable to, e.g., knowledge, costumes, artistic works, etc.

Q4 includes tangible arts and crafts (to which intangible rights may also apply); it may also be extended to apply to natural and genetic resources.

In its latest (2011) proposals on this issue, WIPO prefers to distinguish secret (as opposed to sacred) from non-secret TK. ${ }^{72}$ Arguably this is more practicable: a sacred practice may be kept secret. However, if its custodians have no objection to its public use, then presumably they may not require any specific legal protection to keep it from others. According to the proposed WIPO text, in respect of secret TK, beneficiaries of the right 'should have the means, through adequate and effective [legal and practical] appropriate measures, to prevent any unauthorized fixation, disclosure, use, or other exploitation' ${ }^{73}$ Independently of this debate on secret versus sacred, it seems rather self-evident that GIs will not be of much use for TK on the left-hand side of the matrix. GIs could, however, apply to some forms of secular or commercially exploitable forms of expressions of TK - that is, the right-hand side of the matrix.

The protection of GIs to assist in the development of traditional innovation is admittedly a limited tool. The following diagram (Figure 7) may help explicate the issues:

72 WIPO IGC Secretariat, The Protection of Traditional Cultural Expressions: Draft Articles, WIPO Doc WIPO/GRTKF/IC/18/4 (2011).

73 Ibid, proposed art $3 \mathrm{~A}$. 
Figure 7. The intersections of commerce, technology and culture

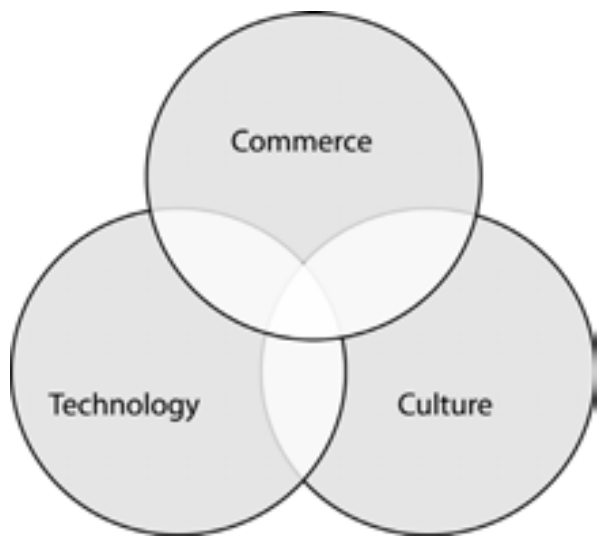

In this diagram, culture must be defined broadly as the relationship with the land that forms part of a culture, but also to the very preservation of that land, including its biodiversity. The intersections in our diagram are instructive. The intersection between culture and commerce, for instance, happens when a traditional product, one in which a traditional culture is embedded, is marketed and becomes (potentially) subject to market forces. This is not incompatible with Traditional Innovation, the dynamic nature of which one cannot deny. However, this may lead to the intensification of the exploitation, in particular for agricultural-based products.

Technology might be brought to bear to intensify exploitation and increase outputs, thus generating additional income but increasing risks of changes to the traditional product and overexploitation of the land. The question becomes one of stewardship, community empowerment and the role of the state in protecting traditional communities (or not) against those risks. ${ }^{74}$

Traditional innovation itself may often be situated at the intersection of 'culture' and technology. By contrast, GIs are generally situated at the intersection of culture and commerce though in many cases also at the triple intersection (with technology). The main focus of GIs is on commercialisation, not preservation of the underlying knowledge. The additional resources that exploitation might

\footnotetext{
74 The Preamble to the TRIPS Agreement refers to intellectual property rights as private rights, a statement mostly designed to limit obligations of state enforcement of those rights. In the case of GIs, the communal (or state) ownership of the right and the link with broader cultural and societal aspects make GIs a special category of intellectual property, at least where they are protected not as simple trademarks but under a sui generis regime. Here the question is basically who decides if changes to an existing traditional product is acceptable, and on what basis.
} 
generate can help with preservation but they may also induce changes to increase efficiency that will in turn affect the product and underlying 'culture'. As such, commercialisation may in some cases make preservation more difficult. ${ }^{75}$

In New Zealand, for example, the way in which mātauranga Māori forms part of whakapapa; the custodianship (kaitiakitanga) of iwi, hapū (and perhaps individual whānau); and the forms of use (for example, the use of rongoā by tohunga) are all testimony to the fact that, while commercial exploitation of mātauranga Māori is not organically incapable — and certainly not unworthy of commercial exploitation, that form of use has not been a primary driver for the preservation and development of mātauranga Māori. ${ }^{76}$ Additionally, the sacred/ secular and secret/non-secret distinction is not always easy to superimpose on knowledge that is typically situated and contextual. ${ }^{77}$ Yet resort to GIs might be appropriate for commercially exploited traditional innovation that outsiders might describe as secular or non-secret. As I discuss below, this requires some perhaps unpalatable 'packaging' of TK to fit the GI scheme.

In spite of those important shortcomings, the protection of GIs meshes well with several, perhaps most, of the normative concerns identified by WIPO in its efforts to design an international framework for non-secret TK protection. More specifically, it meshes with respect for traditional cultural expressions (TCEs), which WIPO defines as 'any form, tangible or intangible, or a combination thereof, in which traditional culture and knowledge are embodied and have been passed on [from generation to generation],tangible or intangible forms of creativity of the beneficiaries' ${ }^{78}$ This includes stories, epics, legends, poetry, riddles and other narratives; words, signs, names and symbols; musical or sound expressions, such as songs and instrumental music, and the sounds which are the expression of rituals; dances, plays, ceremonies, rituals, rituals in sacred places; games, puppet performances, and other performances, whether fixed or unfixed; expressions of art; and architecture and tangible spiritual forms, and sacred places. ${ }^{79}$

There would be much to say about this list and its juxtaposition with copyright, if the term 'expression' were replaced with 'work'. 'Expressions' might be seen here as über-works, rights in which would belong to a community and may

\footnotetext{
75 The resources generated by commercialisation may also create the resources/interest in maintaining some food/drink-making and other traditions.

76 I found the traditional approach to rongoā illustrative of the reductionist view of medicine and dominant Western memes in that respect. Few Western doctors - and fewer patients still — would argue that life-saving medicines have only a commercial value. They obviously have much broader social and spiritual implications. 77 See M Leiboff, 'Law's Empiricism of the Object: How Law Recreates Cultural Objects in its Own Image' (2007) 27 The Australian Feminist Law Journal 23, 23-24.

78 WIPO IGC Secretariat, The Protection of Traditional Cultural Expressions: Draft Articles, above n 72 , annex at 4 .

79 Ibid.
} 
not expire. This difficult cohabitation has been discussed at length elsewhere. Moreover, most forms of intellectual property (designs, patents and so on) are vulnerable to the same critiques. By contrast, a permanent right (or non-expiring right after a certain date) belonging to a community is precisely what a GI is.

I suggest that there are many other forms of TK that may be commercially exploited and in which a 'TK rent' could be captured by a GI. Traditional knowledge more generally is defined in the latest draft WIPO document as:

[I]ntellectual activity in a traditional context, and includes the know-how, skills, innovations, practices and learning that form part of traditional knowledge systems, and knowledge embodying traditional lifestyles of indigenous and local communities, or contained in codified knowledge systems passed between generations and continuously developed following any changes in the environment, geographical conditions and other factors. It is not limited to any specific technical field, and may include agricultural, environmental and medicinal knowledge, and any traditional knowledge associated with cultural expressions and genetic resources. ${ }^{80}$

\section{(b) Packaging TK as Gls to Promote Innovation}

There are several forms of TK that might thus lead to traditional innovation. Indeed, the use of GIs to generate 'development from within' is not new, although it was mostly advocated for the 'global south' ${ }^{81}$ GIs have been linked to rural development in particular, and this may be compatible with many forms of indigenous innovation and production. ${ }^{82}$

Several indigenous communities have developed sustainable land use and conservation models that are viewed by some environmental advocates as possible 'organic' alternatives to pouring billions of tons of chemicals into the ground. ${ }^{83}$ Certain forms of environmental TK could be 'packaged' as bestpractice models using GIs, much in the way that Leadership in Energy and Environmental Design standards have evolved over the past decades for 'green

80 WIPO IGC Secretariat, The Protection of Traditional Knowledge: Revised Objectives and Principles, WIPO Doc WIPO/GRTKF/IC/18/5 (2011), annex at 18 [emphasis added].

81 See S Bowen, 'Development from Within? The Potential for Geographical Indications in the Global South' (2010) 13(2) Journal of World Intellectual Property 231, 233.

82 See P van de Kop et al (eds), Origin-Based Products: Lessons for Pro-Poor Market Development (Royal Tropical Institute and French Research Centre for International Development (CIRAD, 2006); and C Fink and B Smarzynska, 'Trademarks, Geographical Indications and Developing Countries' in B Hoekman et al (eds), Development, Trade, and the WTO: A Handbook (World Bank, 2002) 403.

83 See, for example, Small Grants Programme, 'Replacement of Chemical fertilizer and pesticide by organic farming for sustainable production of vegetable crops' (IND/SGP/OP4/Y2/RAF/2009/34/BHR 05) <http://sgp. undp.org/web/projects/14100/replacement_of_chemical_fertilizer_and_pesticide_by_organic_farming_for_ sustainable_production_of_ve.html> 
building' certification. ${ }^{84}$ A possible example is the mosaic method of burning land used by indigenous peoples in Australia. ${ }^{85}$ A GI might apply to methods certified by custodians of this knowledge even if transported to a different technological domain, such as mosaic burning using helicopters. ${ }^{86}$

Another form of traditional innovation might come from greater respect for the use of genetic resources. Those resources seem quintessentially linked to the land they originate from and thus natural candidates for GIs when exploited commercially or, indeed, to prevent their appropriation. One of the aspirational objectives suggested by WIPO in this context is to 'curtail the grant or exercise of improper intellectual property rights over traditional knowledge and associated genetic resources'.$^{87}$ In a separate set of proposals dealing specifically with genetic resources, one of the options identified by WIPO is to '[e]nsure those accessing/using genetic resources and associated traditional knowledge comply with requirements for prior informed consent and fair and equitable benefitsharing, including customary laws and procedures of the communities' ${ }^{88}$ Some scholars point to the example of Maytenus buchaniti, a plant from the Shimba Hills of Kenya from which the US National Cancer Institute (NCI) developed a drug known as maytansine. ${ }^{89}$ While over twenty-seven tons of the shrub were collected, no agreement was made to either share or acknowledge its origin. A similar situation arose over the collection of Homalanthus nutans in the Samoan rainforest. In both cases, the work of the NCI was reportedly based at least in part on traditional medicinal knowledge about the plants. ${ }^{90}$

The use of a GI could potentially play a slightly different role here - namely to acknowledge both origin as such and the fact that a benefit-sharing agreement is in place - if the use of the GI was authorised by its holder only after the successful conclusion of such an agreement. This type of GI protection seems consonant with efforts to get patent holders to disclose the origin of genetic resources used during the invention process. ${ }^{91}$

84 See See US Green Building Council, What LEED Is (2012) < http://www.usgbc.org/DisplayPage. aspx?CMSPageID $=1988>$

85 See Department of Sustainability and Environment, Landscape Mosaic Burns: Land and Fire Management Information Sheet (2010) <http://www.land.vic.gov.au/CA256F310024B628/0/58AF2C45BEF36828CA2577490 00BE0D2/\$File/landscape+mosaic+burning_factsheet_JUN10.pdf $>$

86 See H Verran, 'A Postcolonial Moment in Science Studies: Alternative Firing Regimes of Environmental Scientists and Aboriginal Landowners' (2002) 32(5-6) Social Studies of Science 729, 745.

87 WIPO IGC Secretariat, above $\mathrm{n} 72$, annex at 6.

88 WIPO IGC Secretariat, Draft Objectives and Principles Relating to Intellectual Property and Genetic Resources at IWG 3, WIPO Doc WIPO/GRTKF/IC/18/9 (2011), annex at 3.

89 See W Pretorius, 'TRIPS and Developing Countries: How Level Is the Playing Field?' in P Drahos and R Mayne (eds), Global Intellectual Property Rights: Knowledge, Access and Development (Palgrave Macmillan/ Oxfam, 2002) 183, 186.

90 See ibid and D Posey and G Dutfield, Beyond Intellectual Property (IDRC, 1996), 35.

91 See P Drahos, 'A Networked Responsive Regulatory Approach to Protecting Traditional Knowledge' in D Gervais (ed), Intellectual Property, Trade and Development (Oxford University Press, 2007) 385, 404. 
Indigenous Peoples' Innovation

This use of GIs on indigenous products might also coincide normatively with fair trade issues, although the two should not be confused. ${ }^{92}$ GIs more generally feed into the 'quality turn' in consumer preferences and the emergence of 'values-based' labels. ${ }^{93}$

\section{(c) Meeting the WIPO TK/TCEs Protection Objectives}

WIPO identifies several objectives that the protection of TK/TCEs should aim to achieve. These objectives seem consonant with GIs, perhaps more so than other intellectual property rights. Let us take a brief look at the most relevant aims in the WIPO proposal.

\section{(i) Recognise value}

This first aim is described as the recognition that indigenous peoples and communities and traditional and other cultural communities consider their cultural heritage to have intrinsic value, including social, cultural, spiritual, economic, scientific, intellectual, commercial and educational values...' GIs capture and reflect the value that a community places on a product because of its origin. It embodies the 'land' in the product much as authors' rights embody the Hegelian 'author' in the work.

\section{(ii) Promote respect}

The second aim is 'to promote respect for traditional cultures and folklore, and for the dignity, cultural integrity, and the philosophical, intellectual and spiritual values of the peoples and communities that preserve and maintain expressions of these cultures and folklore'.$^{94}$ The GI is a symbol of the origin of the product, and the fact that consumers both recognise this origin and are willing to pay for it is arguably a mark of respect, but at the very least it might afford economic tools to the custodians to help them preserve and maintain the knowledge embodied in the making of the product and perhaps others forms of TK.

\section{(iii) Meet the actual needs of communities}

This aim, to be 'guided by the aspirations and expectations expressed directly by indigenous peoples and communities and by traditional and other cultural communities, respect their rights under national/domestic and international law,

92 A Taubman, 'Thinking Locally, Acting Globally: How Trade Negotiations over Geographical Indications Improvise "Fair Trade" Rules' (2008) Intellectual Property Quarterly 3.

93 See D Goodman, 'Rural Europe Redux? Reflections on Alternative Agro-Food Networks and Paradigm Change' (2004) 44(1) Sociologica Ruralis 3. See also P Drahos, above n 91, 402-403.

94 WIPO IGC Secretariat, above $\mathrm{n} 72$, annex at 1 . I will use quotes from this document but the objectives identified in respect of TCEs closely parallel those on TK more broadly. See the WIPO IGC Secretariat, above n 78, annex at 3-7. 
and contribute to the welfare and sustainable economic, cultural, environmental and social development of such peoples and communities' ${ }^{\prime}{ }^{95}$ is likewise well served for some forms of TK. The GI registration process is itself an expression of the aspiration and expectation that the product, and specifically the natural and human factors at its point of origin, should be protected, and its exploitation might contribute to the welfare of the community of origin.

\section{(iv) Prevent the misappropriation and misuse of traditional cultural expressions}

This aim is defined as providing indigenous peoples and communities and traditional and other cultural communities with the legal and practical means, including effective enforcement measures, to prevent the misappropriation of their cultural expressions [...] and [control] ways in which they are used beyond the customary and traditional context and promote the equitable sharing of benefits arising from their use'. ${ }^{96}$ An internationally recognised GI would arguably prevent the use of tradition and know-how embodied in a product, with or without consumer confusion. It is clearly designed to tackle use outside the community, notably when the product enters (international) channels of commerce. Whether the use is a misappropriation without consumer confusion is a separate debate. Increasingly, however, the need for confusion is disappearing as the mooring of trade mark law as global brands get protection well beyond the traditional contours of passing off. ${ }^{97}$ This is normatively questionable for pure commercial marks, in particular as it affects freedom of expression. However, the Lisbon system is a high form of protection that recognises the special nature of GIs (even where they might be protected under a trade mark regime).

\section{(v) Empower communities}

The aim is to find a balanced and equitable yet effective manner to empower 'indigenous peoples and communities and traditional and other cultural communities to exercise in an effective manner their rights and authority over their own traditional cultural expressions'. GIs must be balanced against other concerns, including freedom of expression and consumer interests. I am certainly not suggesting a watertight right that would go beyond what is required to achieve the aim of protecting equitably the legitimate interests of the holder and custodians. In the Lisbon context, the debates have focused not on conflicts with, say, (other) human rights, but on conflicts with trade marks appropriating pre-existing GIs (often in good faith). ${ }^{98}$

\footnotetext{
95 WIPO IGC Secretariat, above n 72.

96 Ibid.

97 See M Lemley and M McKenna, 'Irrelevant Confusion' (2010) 62 Stanford Law Review 413.

98 The most famous is the conflict between Anheuser-Busch 'Budweiser' and Budweiser, the Germanlanguage term for bier from the Budějovický brewery in the Czech Republic. Parties split the two most
} 


\section{(vi) Contribute to safeguarding traditional cultures}

WIPO suggests that TK/TCE protection 'should contribute to the preservation and safeguarding of the environment in which traditional cultural expressions are generated and maintained, for the direct benefit of indigenous peoples and communities and traditional and other cultural communities, and for the benefit of humanity in general'. GIs may contribute to this aim by making the preservation and maintenance of the knowledge associated with the making of a GI product easier.

\section{(vii) Encourage community innovation and creativity}

This aim is to 'reward and protect tradition-based creativity and innovation especially by indigenous peoples and communities and traditional and other cultural communities'. GIs function mostly as guarantors of tradition. Yet, as products enter channels of commerce, innovation might be more easily rewarded - for example, in the creation of versions of the products that combine GIprotected knowledge and new ideas.

\section{(viii) Contribute to cultural diversity}

This aim is to 'contribute to the promotion and protection of the diversity of cultural expressions'. Having access to more products produced in local communities around the world might contribute to this objective by making consumers more aware of the cultural aspects at the point of origin which infuse

recent decisions. Anheuser-Busch Inbev essentially won a case before the European Court of Justice (Grand Chamber) decided on 8 September 2009 (Case C 478/07). The Court decided that EC law was exhaustive in respect of appellations for beer and that additional protection in a bilateral agreement between Austria and the Czech Republic was ineffective. Earlier, on 16 December 2008, the Court of First Instance of the European Communities (CFI) overturned four decisions by the Board of Appeal of the Office for Harmonisation in the Internal Market (OHIM). See Budějovický Budvar v Office for Harmonisation in the Internal Market (Trade Marks and Designs), Joined Cases T 225/06, T 255/06, T 257/06 and T 309/06, 16 December 2008. For a discussion of the judicial saga, see N Resinek, 'Geographical Indications and Trade Marks: Coexistence or "First in Time, First in Right" Principle' (2007) 29 European Intellectual Property Review 446, 447. The crux of the debate in the Court of First Instance was whether the appellant had shown it was the proprietor of a sign 'of more than mere local significance. 'Use', as the Court rightly noted (and, on this point, agreeing with the OHIM Board), means 'genuine use of a trade mark where the mark is used in accordance with its essential function, which is to guarantee the identity of the origin of the goods or services for which it is registered, in order to create or preserve an outlet for those goods or services; genuine use does not include token use for the sole purpose of preserving the rights conferred by the registration.' (CFI Opinion, para 161.) In a somewhat unconvincing twist, the Court then found that this rule, which it says applies to earlier trade marks, did not apply to 'when, as in the present case, the sign is an appellation of origin registered under the Lisbon Agreement or an appellation protected under the bilateral convention', see ibid, para 163. If one were to accept this conclusion of law, (not necessarily) genuine use in one European Union member state whose law does not protect a given appellation may be combined with the legal protection available in a different member state where no facts establish use (whether genuine or not). Concerning the 'not merely local' requirement, the Court limited itself to a finding that protection under Lisbon in a country other than the country of origin is sufficient, even, it seems, without any factual evidence, see ibid, para 181. 
the product with special value and, generally, by insisting on the importance of less uniform sources for food and other GI products. This feeds into the desire expressed by many consumers to know more about what they eat and drink. ${ }^{99}$

\section{(ix) Promote the [community] development of indigenous peoples and communities and traditional and other cultural communities and legitimate trading activities}

For reasons that are discussed above, GIs would likely 'promote the use of traditional cultural expressions for the [community based] development of indigenous peoples and communities and traditional and other cultural communities'.

\section{(x) Preclude unauthorised intellectual property rights}

This aim was mentioned above. It is more an effect than a normative claim. GIs would 'preclude the grant, exercise and enforcement of intellectual property rights acquired by unauthorized parties over traditional cultural expressions and [derivatives] [adaptations] thereof'. This does not avoid, however, the need to deal fairly with issues concerning pre-existing trade marks. In addition, if 'unauthorized' is extended to mean use of genetic resources without a benefitsharing agreement in place, then use of a GI that would increase value and benefit all those involved in the distribution chain could be licensed only if such an agreement was in place. Conversely, one must prevent the use of GIs to misappropriate the GI rent that is associated with a specific origin. ${ }^{100}$

If a GIs system is implemented as a certification of collective mark, which the Lisbon Agreement allows, typically the state will not check the validity of the claimant's rights. This may increase the risk of misappropriation.

\section{(xi) Enhance certainty, transparency and mutual confidence}

The final aim is to enhance 'certainty, transparency, mutual respect and understanding in relations between indigenous peoples and communities and traditional and cultural communities, on the one hand, and academic, commercial, governmental, educational and other users of traditional cultural expressions, on the other'. It might be served by providing proper recognition for the value of the origin of a product based on tradition. Respect is often the first and most important step to a fruitful dialogue.

99 See D Giovannucci et al,'Defining and Marketing "Local" Foods: Geographical Indications for US Products' (2009) 12 Journal of World Intellectual Property 6.

100 This issue is distinct from the multiple claims of 'ownership' of the same GI, which is discussed in the next section below. 
In sum, the protection of GIs, properly calibrated, could serve the aims identified by WIPO (after years of serious deliberation on the issue) that the protection of TK should strive to achieve.

\section{(d) Issues}

The use of GIs will not go forward without significant issues, however. These will emerge in any scenario where a collective right is established or recognised. The major issue might be one of ownership, meant here as the authority to license the use of a GI. Because GIs are anchored in the land, forced displacements of indigenous peoples (due to colonisation, for example) or 'artificial' colonial borders that do not map well over actual land use might lead to conflicts of ownership. As with the Pisco issue between Chile and Peru, there are potential sharing arrangements that could be negotiated. ${ }^{101}$ Admittedly, the optimal use of GIs also relies on the assumption that a collective ownership arrangement can in fact be established even without a conflict among two peoples, clans, and so on.

Another troubling prospect is the capture of a GI by 'powerful extralocal actors', as was apparently the case with an otherwise very successful GI, Tequila. ${ }^{102}$ This and the ownership issue mentioned previously are examples of what might be referred to more generally as issues of governance. This supports the case for a strong but fair involvement by the state. ${ }^{103}$

A second set of problems is the possible emergence of micro-GIs. While microGIs, like (micro-)niche products are not necessarily a negative, the risk is that they might overcrowd the GI space for a specific product class if each clan, tribe, nation and so on has a version of what is perceived as essentially the same thing. As the product use moves further from its point of origin, this may become more acute. French consumers may be familiar with hundreds of wine appellations, for example, but that may not be true elsewhere. A single GI system, even if international by design, needs to be used globally for every GI, however. There are three 'circles' of erga omnes protection. A first circle would be to the territory of origin; another would be a regional circle - or perhaps a non-geographically delimited circle of like-minded countries taking similar or compatible approaches to the protection of TK. A third possible circle would be an extension to all WIPO and/or WTO members. Naturally, the first level can be established by a local law. The second circle requires a regional or sectoral

\footnotetext{
101 See above $\mathrm{n} 30$.

102 Bowen, above $\mathrm{n} 81,235$. There have been conflicts for decades between growers of agave and Tequila bottlers on issues such as the minimum required proportion of agave for Tequila to bear the name, and the exportation of bulk Tequila (tequila mixto). That said, GIs cannot be either delocalised or outsourced.

103 Bowen, above n 81, 243-244.
} 
agreement, providing for (for example) reciprocal protection. Yet all three can make use of an international system, even if not all micro-GIs are used globally. In my view, the real challenge is to successfully pick and use some GIs globally without overcrowding.

\section{A Protocol to the Lisbon Agreement as TK Protection}

\section{(a) Towards a Protocol}

We have now seen the two existing international frameworks for GIs (Lisbon and TRIPS) and demonstrated that GIs might serve the needs of custodians of TK. In our look at Lisbon, we saw that the system is not widely subscribed to, especially in the 'New World', owing to real or perceived deficiencies. A second level of enquiry is to ask how TRIPS and Lisbon should interface. A protocol to the Lisbon Agreement could certainly ameliorate and revitalise the current system. I also suggest that it could and should tackle the interface issue in a way that reflects the concerns and interests of TK custodians and users.

The question to ask at this juncture is whether a protocol is realistic to begin with, and then how would it interface with TRIPS norms. In a recent paper, I argued that there were two ways to proceed. The first I termed Lisbon Light. Under this approach, WTO members would establish a new international register, possibly limited to wines and spirits, to be administered by WIPO, thus relying on the expertise of the Lisbon staff and, more generally, on WIPO's experience in administering international intellectual property registration systems. The protocol would mirror the current registration process but apply to GIs (copying the TRIPS definition) and contain no substantive protection norms. Essentially, under this approach a new multilateral system is established but most substantive rules set aside, thus allowing TRIPS and the WTO dispute settlement system to fill the gap. This would be of little help as TK protection, especially if limited to wines and spirits.

The second approach (which I favour) I called a TRIPS Zero protocol. Under this second approach, WIPO members would adopt a protocol that mirrors not just the administrative provisions of the current Lisbon system but also the TRIPS provisions concerning GIs, and conflicts between GIs and trade marks. ${ }^{104}$ The register would be open to all products.

104 Naturally, 'TRIPS provisions' is potentially a dynamic notion, as TRIPS may be amended in the future. An amendment to the TRIPS Agreement was adopted by a decision of the WTO General Council of 6 December 2005, art 31 bis. See Amendment to the TRIPS Agreement, WTO Doc WT/L/641 (2005). 


\section{(b) Applicable Precedents}

There are clear precedents. First, in 1989 a Protocol to the 1891 Madrid Agreement Concerning the International Registration of Marks was adopted. ${ }^{105}$ More countries are party to this Protocol (83) than to the original Agreement (56). ${ }^{106}$

The core idea is simple: step out of the historical flange-ways and known road blocks, and thus avoid the related path dependency which has manifested itself in suigeneris regimes with particular attributes, such as their variable precedence over prior marks, and establish a true multilateral register for denominations of origin to which products owe specific qualities, characteristics and indeed their reputation in the marketplace.

On the substantive side, a second relevant precedent is the addition of TRIPScompatible norms in new WIPO instruments. A recent precedent is the adoption of two 'Internet' treaties in $1996 .{ }^{107}$

Clearly, no country should have to adhere to the Lisbon Agreement to adhere to the Protocol, and not just countries could join. A full revision would also make it possible for intergovernmental bodies, such as the European Union, to join. ${ }^{108}$

\section{(c) Application to Other Products}

The question of the application of a new register to products other than wines and spirits must be tackled if the needs of TK holders and custodians are to be addressed.

Under TRIPS Article 23.4, the new multilateral register need only apply to wine, although political agreement exists to extend it to spirits. ${ }^{109}$ If WTO members agreed to extend high (Article 23) protection to all products, then the register could be opened to reflect such an extension. Another possibility, which I consider a possible solution to the extension quagmire, is to establish a register with two distinct domains: one for wines and spirits (the traditional domain of appellations), for which Article 23 protection would apply; and one for all other products, for which Article 22 protection would apply (that is, more generally to all 'indications'). In my suggestion, existing Lisbon entries would not be

\footnotetext{
105 Madrid Agreement and Protocol, above n 37.

106 See WIPO, Members of the Madrid Union < http://www.wipo.int/madrid/en/members/>

107 WIPO Copyright Treaty (1996), 2186 UNTS 121; and WIPO Performances and Phonograms Treaty (1996), 36 ILM 76, 86.

108 See P Wilner, 'The Madrid Protocol: A Voluntary Model for the Internationalization of Trademark Law' (2003), 13 De Paul University Journal of Art and Entertainment Law 17, 20-21.

109 See D Gervais, The TRIPS Agreement: Drafting History and Analysis (3rd ed, Sweet \& Maxwell, 2008) 86-97.
} 
extended to protocol members, and the protocol would require a per-country notification (as most other international applications and registrations do), as opposed to applying to all Lisbon Protocol members by default.

\section{(d) Comparison with Most Recent WIPO Proposals}

In March 2011, WIPO released proposed changes to the Lisbon system. ${ }^{110}$ They are in large part consonant with the above analysis and recommendations. The main proposed changes are as follows:

- Allowing members to recognise appellations and/or indications, without having actually to use either term. This is useful mostly on a political level, by allowing members to keep current systems, and a spate system for wines and spirits, on the one hand, and for other products on the other. European legislation recognises both. The practical distinction is less clear.

- An 'entity' should be designated in each member to process international applications for registration, although the source of the right in a given member may be a legislative or administrative act, a judicial decision or national registration. However, under one proposal, federations, associations and other persons could apply directly 'provided that the application is accompanied by a document signed by the competent authority'.

- The protocol would allow intergovernmental organisations (for example, the European Union) to join.

- Finally, the proposals on substantive rights and the priority of prior marks more or less track TRIPS, though not specifically on the spate status of wines and spirits.

Those proposals are a great step in the right direction. They would allow the emergence of a multilateral GI system that could be used for commercially exploited GIs on traditional knowledge, without discrimination as to the type of product and without endangering prior marks used in good faith, subject to specific rules in each member state.

\section{Conclusion}

The aim of this chapter has been to demonstrate that the 1958 Lisbon Agreement on the Protection and Registration of Appellations of Origin could, if properly revised by way of a protocol, function as a multilateral register for GIs of products of all types. This type of collective right is unique in intellectual

110 WIPO IGC Secretariat, Draft Provisions on Certain Matters Addressed by the Working Group in the Context of the Review of the Lisbon System WIPO Doc LI/WG/DEV/3/2 (2011). 
property law, a set of rules developed in Western Europe, with limited input from other industrialised nations, starting in the late nineteenth century and reflecting a belief in the individuality of the author and inventor and of the need to reward and/or protect individuals because of their intellectual contribution. By contrast, the Lisbon Agreement and the related provisions on GIs in the TRIPS Agreement focus on collective knowledge rooted in land and tradition, a notion that may appeal much more naturally to custodians of TK desiring to commercially exploit forms of TK to develop local innovation and improve economic development. This would apply to TCEs such as crafts, as well as to food and to more technical knowledge such as land use and conservation and traditional medicines.

I discussed the possible use of GIs to reflect the presence of an appropriate benefit-sharing and disclosure of origin agreement (as recognised by the right to use the GI). While an amendment to TRIPS on this point seems unlikely, a Doha Round result - if it ever materialises - could include a Ministerial Declaration on this issue. ${ }^{111}$

The chapter also argues that the revision of the Lisbon Agreement should bring it closer to the multilateral register foreseen in Article 23.4 of the TRIPS Agreement. To achieve this goal, I considered the substantive differences between the notions of GI used in TRIPS and of appellation of origin used in the Lisbon Agreement. I also considered the level of protection in Lisbon, and rules concerning conflicts between indications and trade marks, a major sticking point in the development of the international protection of GIs.

I also reviewed the compatibility of GIs with the main aims identified by WIPO (after years of deliberations) that a system to protect TK should achieve, and found a significant degree of consonance between the two. Finally, I applied the relevant findings to the protection of TK and concluded that a TRIPS Zero protocol, reflecting the substantive TRIPS rules in the possible protocol, would be better for TK protection, and noted the existence of credible precedents to show that the conclusion of a protocol is realistic. ${ }^{112}$

111 See D Gervais, ‘Traditional Knowledge \& Intellectual Property: A TRIPS-Compatible Approach' (2005) Michigan State Law Review 137, 160-164.

112 The author has previously published other articles on GIs and the Lisbon Agreement, which contain additional details and information. See 'Reinventing Lisbon: The Case for a Protocol to the Lisbon Agreement' (2010) 11(1) Chicago Journal of International Law 67; Christophe Geiger et al, 'L'Arrangement de Lisbonne, un véhicule pour l'internationalisation du droit des indications géographiques?' (2010) 35 Propriétés Intellectuelles 691; Christophe Geiger et al, 'Towards a Flexible International Framework for the Protection of Geographical Indications' (2010) 1(2) WIPO Journal 147 (English version of previous article); and Daniel Gervais,'The Misunderstood Potential of the Lisbon Agreement' (2010) 1(1) WIPO Journal 87. 